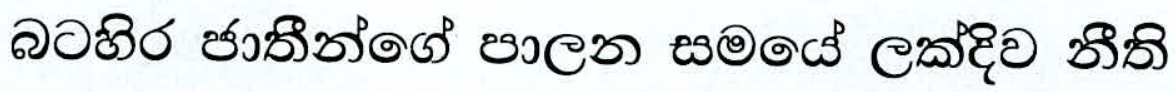

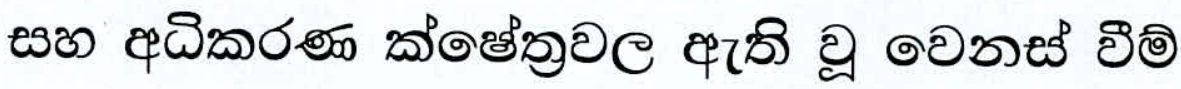

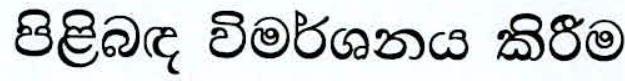

\author{
2014

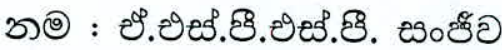

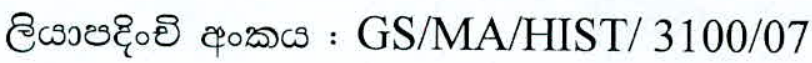

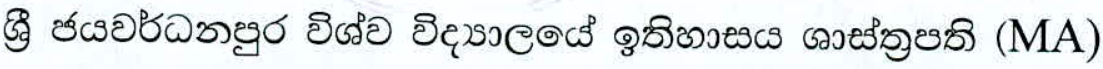

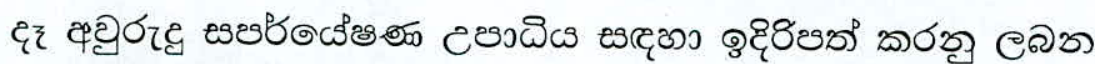

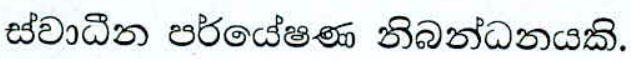




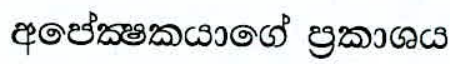

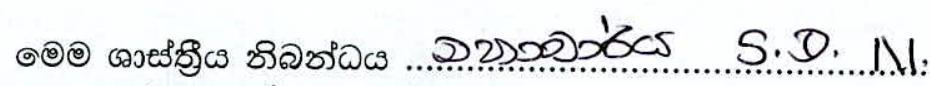

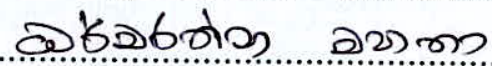

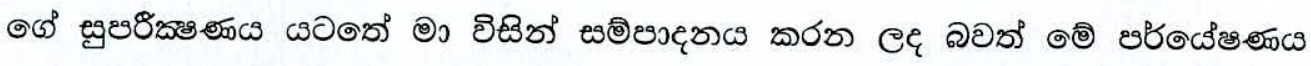

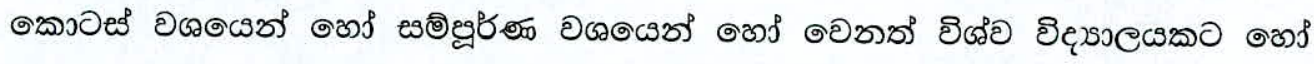

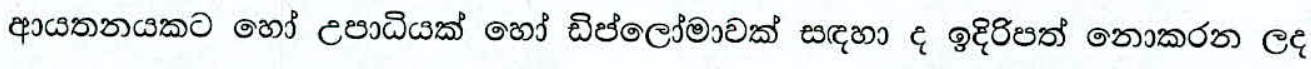

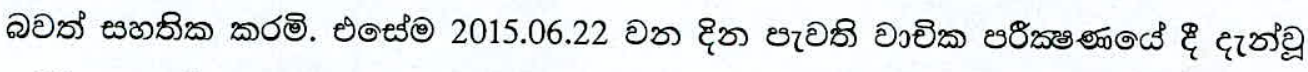

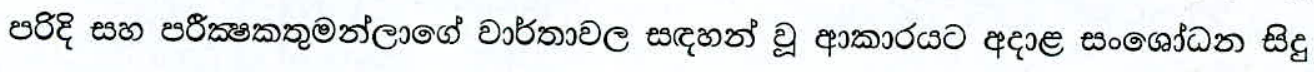

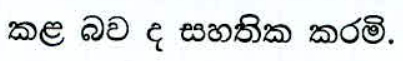

01 .

छे⿻्乛क

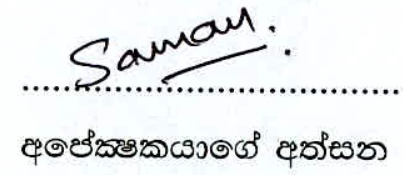




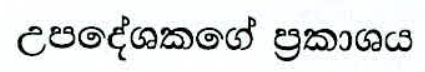

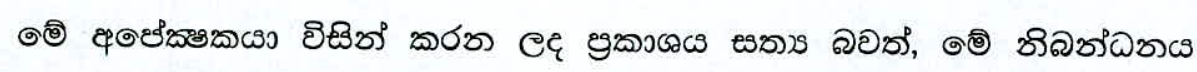

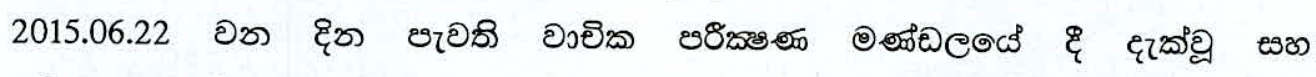

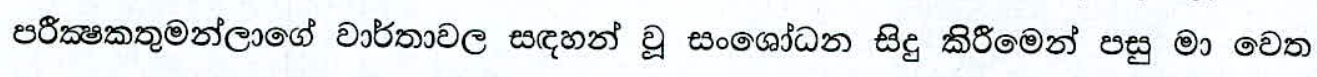

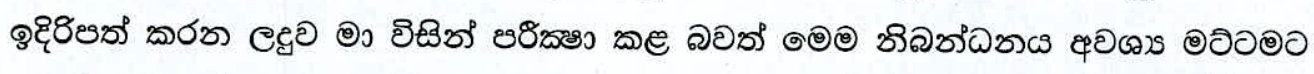

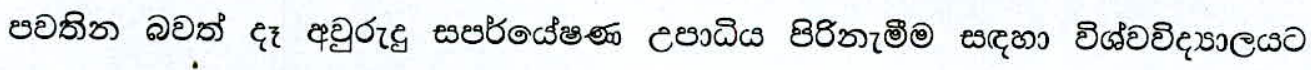

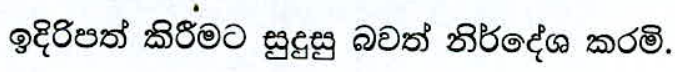

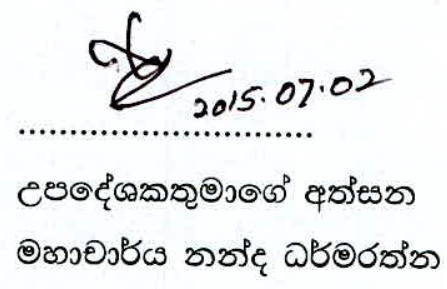




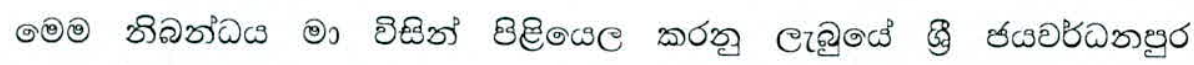

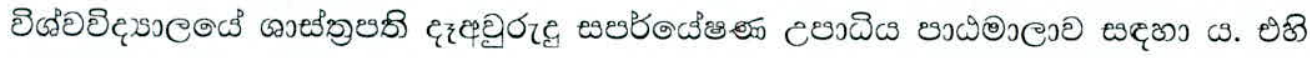

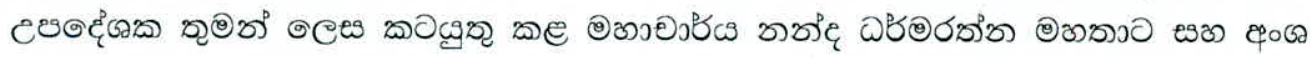

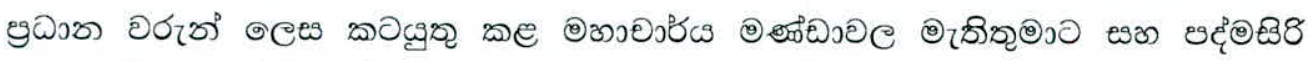

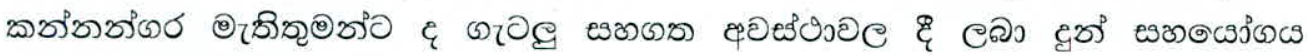

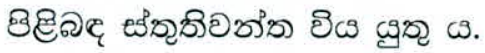

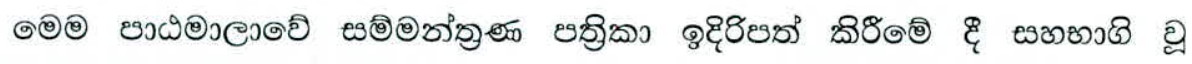

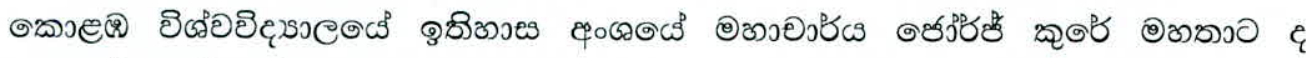

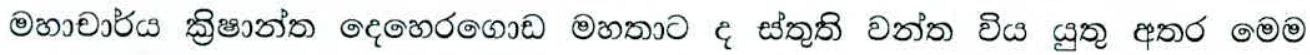

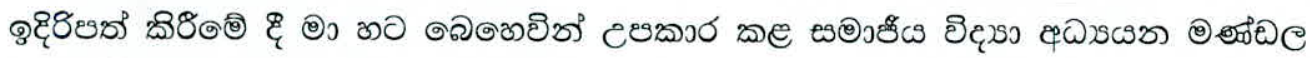

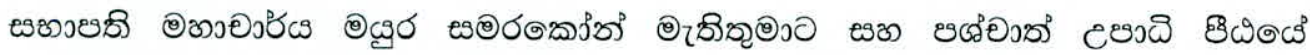

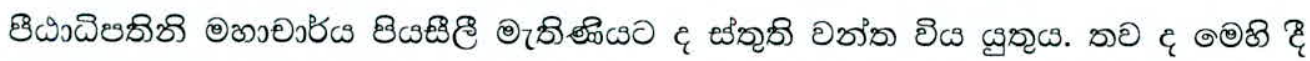

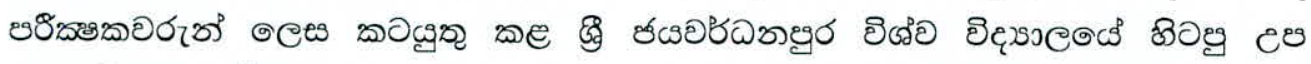

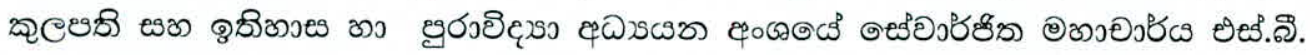

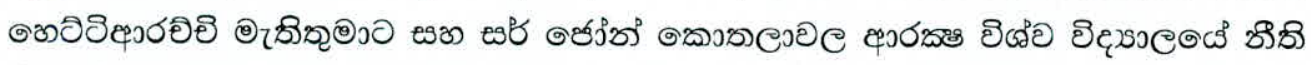

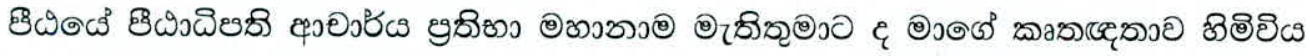

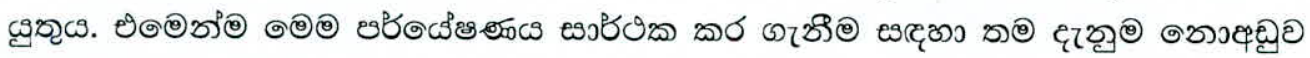

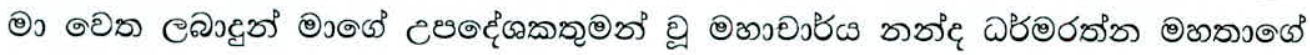

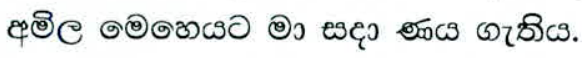

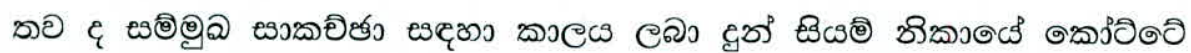

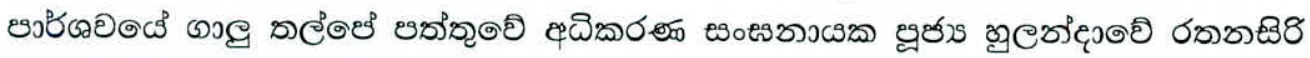

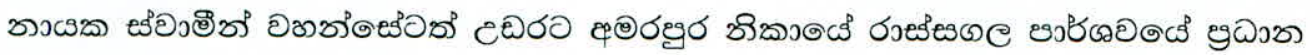

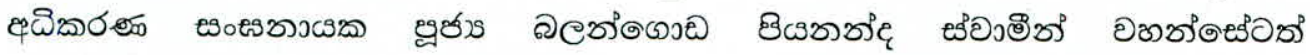

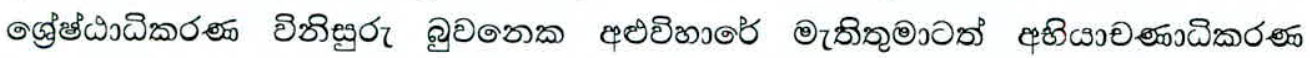

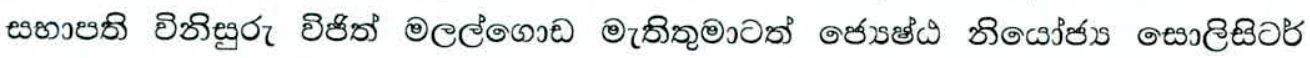

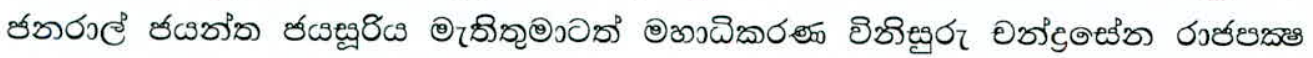

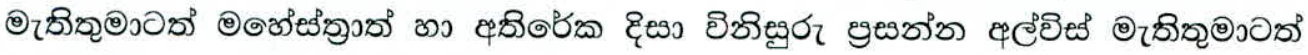

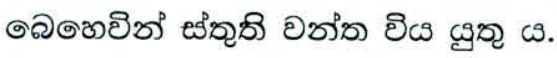

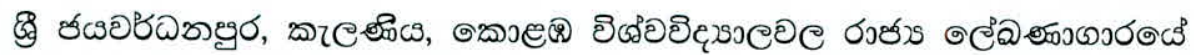

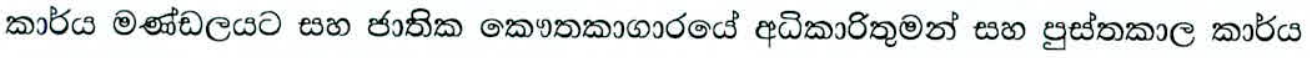

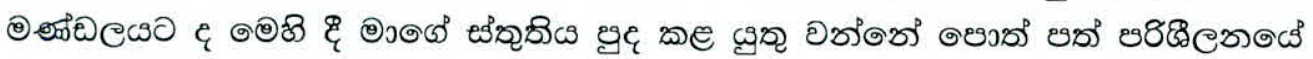

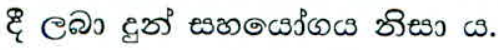




\section{๑றరి ๑దిక్రతి}

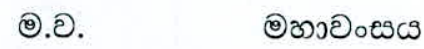

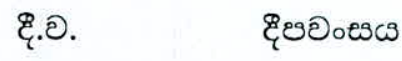

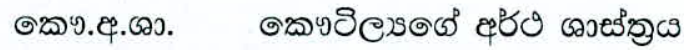

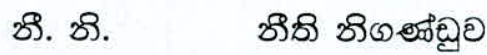

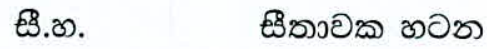

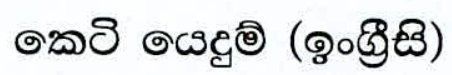

A. J.S.L. Act of Judicature of Sri Lanka

C.B.B. Ceylon Blue Books

C.C. Conquest of Ceylon

C.C.P. Colbrooke Camaroon Papers

C.D. Celon Directory

C.P.C. Civil Procedure Code

Cri. P. C. Criminal procedure code

Dis. Dispatches

E.Z. Epigrapia zeylanica

In.C. Inscriptions of Ceylon

N.L.R. New Law Report

S.L.L.R. Sri Lanka Law Report

S.P. Sessional Papers 
ชอฺุ

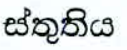

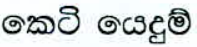

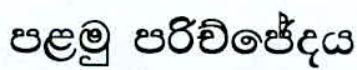

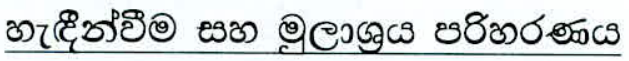

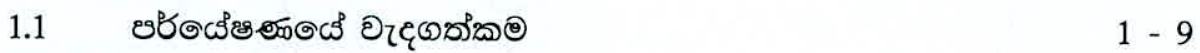

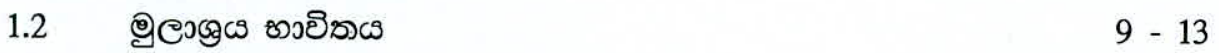

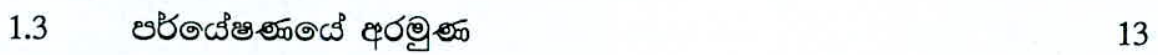

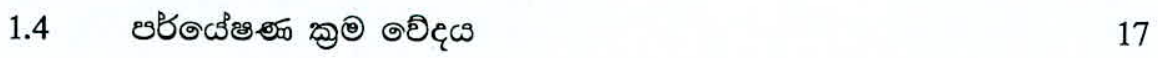

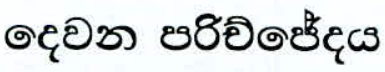

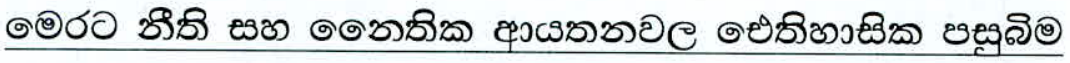

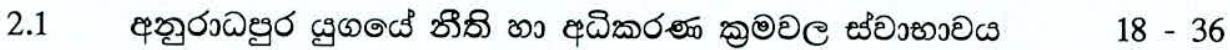

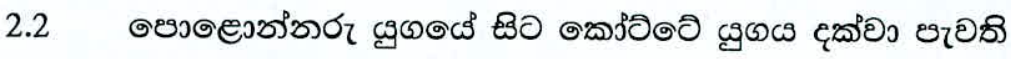

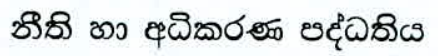

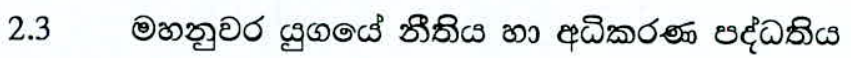

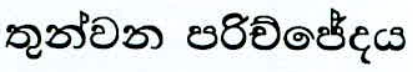

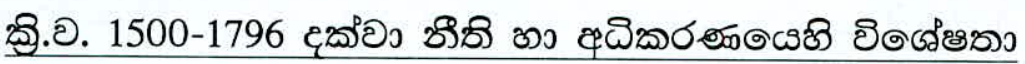




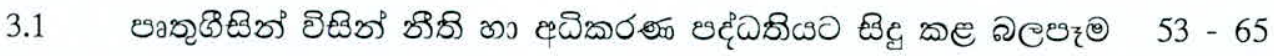

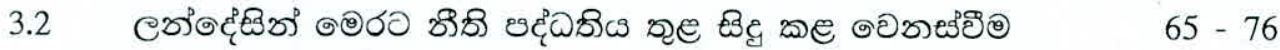

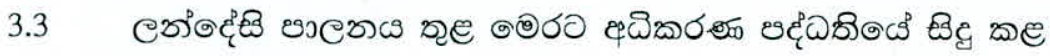
๑อุณรอలอ

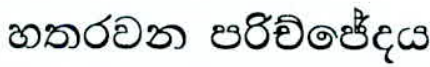

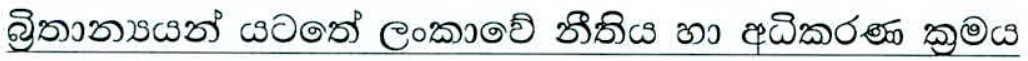

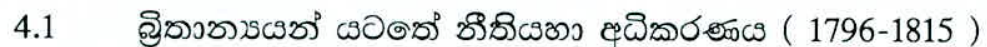

4.21815 ษต్

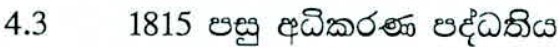

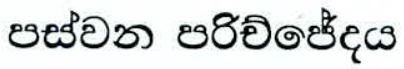

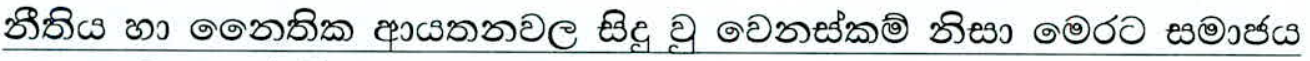

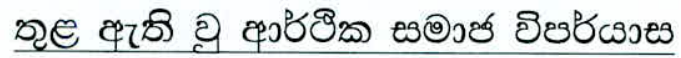

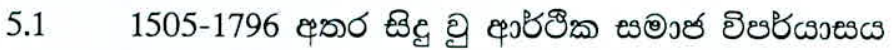

$128-145$

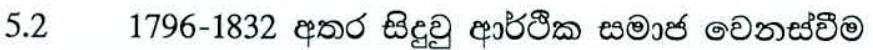

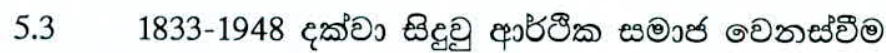

$151-167$

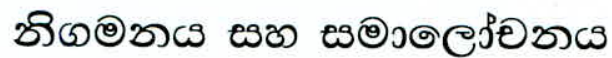

$168-174$

\section{coss}

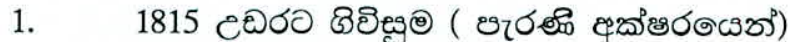

$175-190$

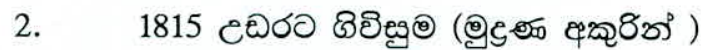

$191-195$

3. 1818 टఉరం

$196-213$

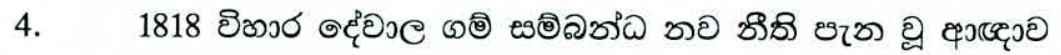

$214-217$

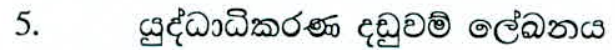

$218-220$

జిమీตอ

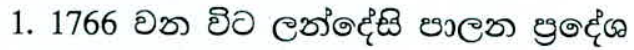

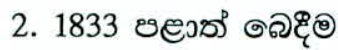




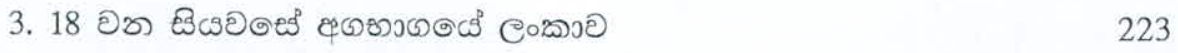

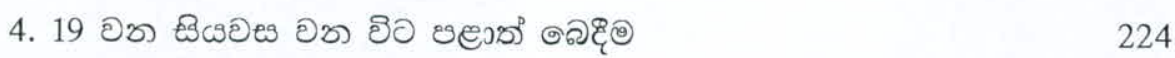

5. క్రి అంญంఠరి అ๐ అృరం (1948) 225

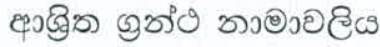

$226-235$ 


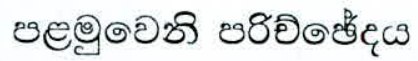

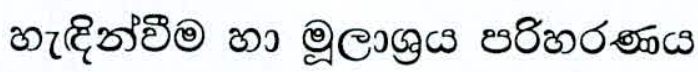

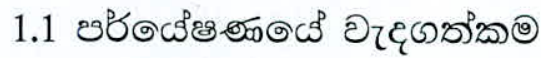

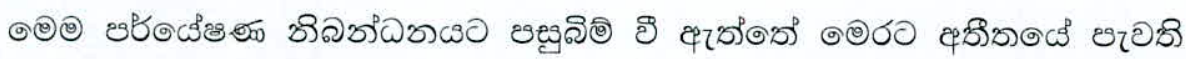

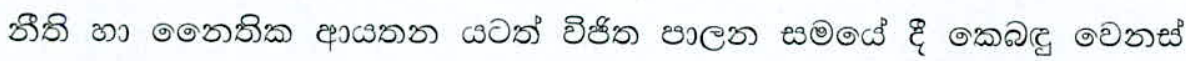

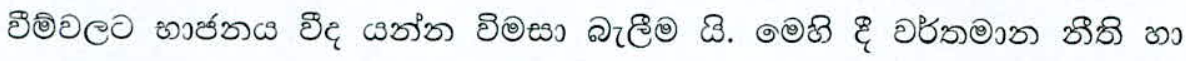

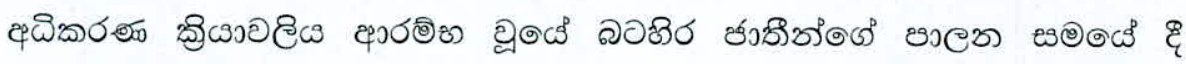

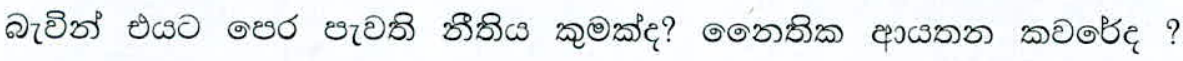

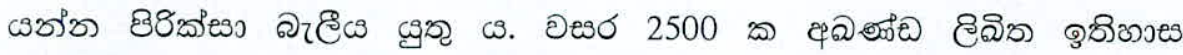

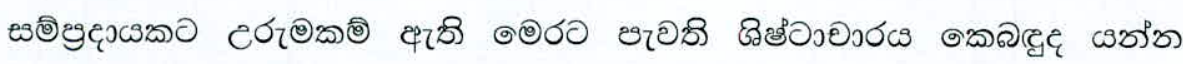

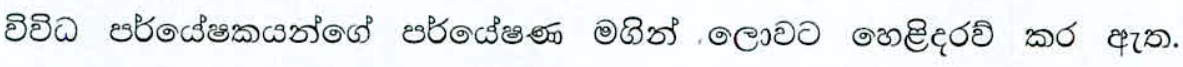

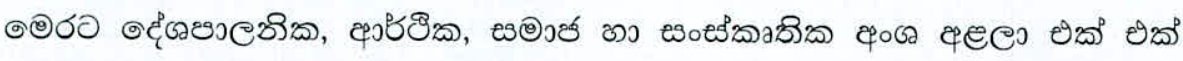

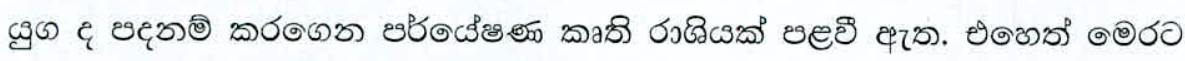

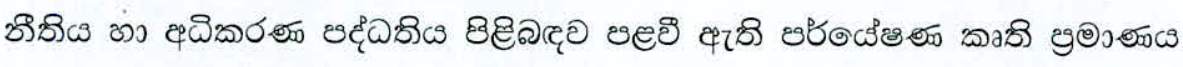

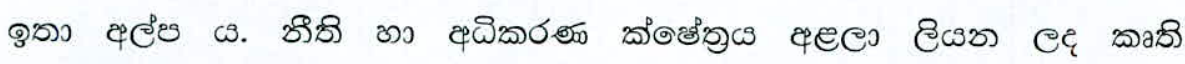

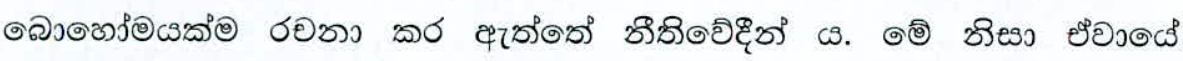

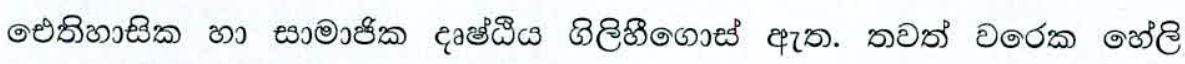

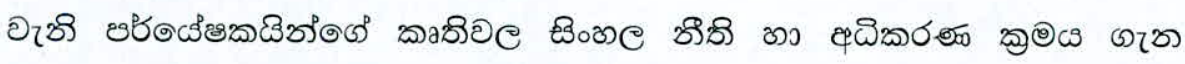

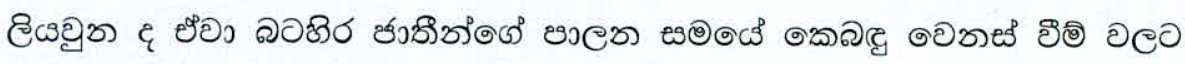

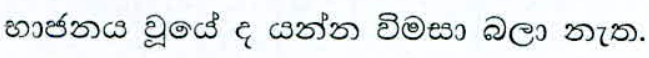

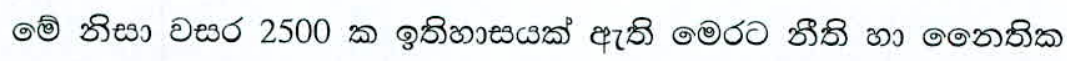

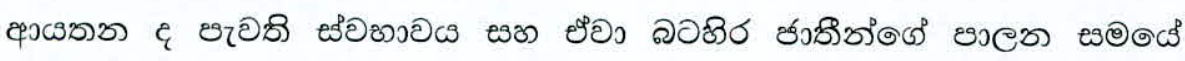

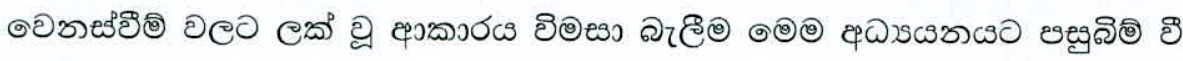

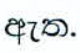

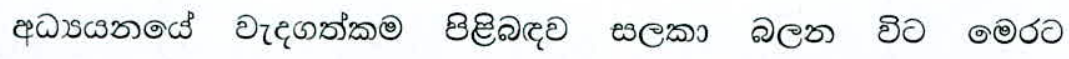

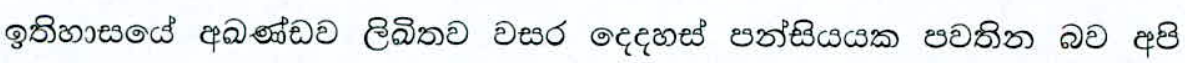

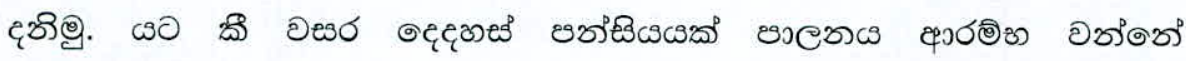

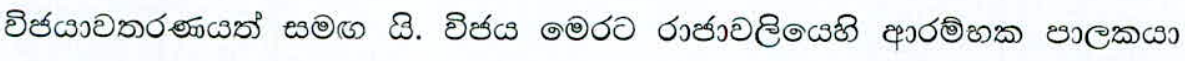

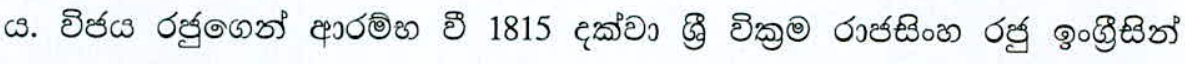

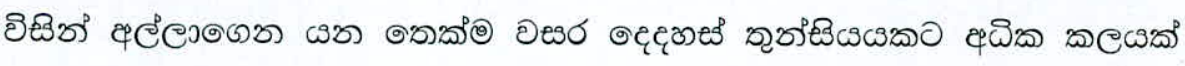




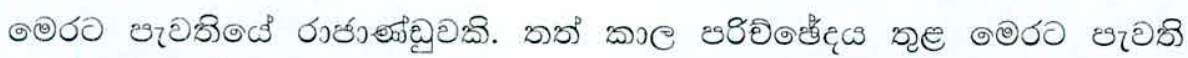

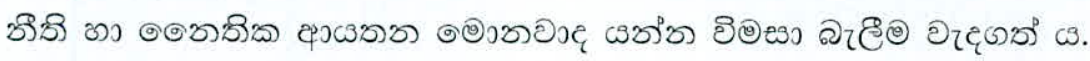

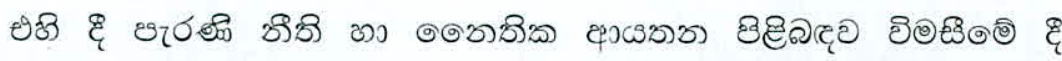

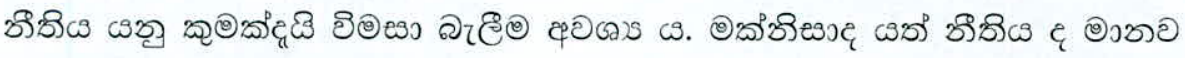

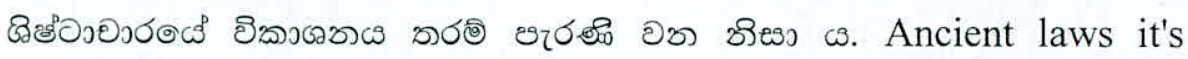

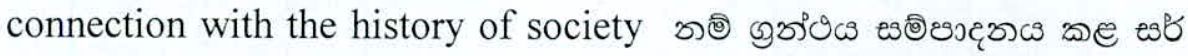

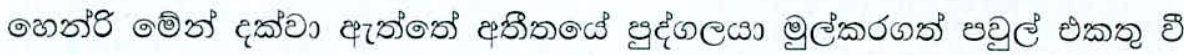

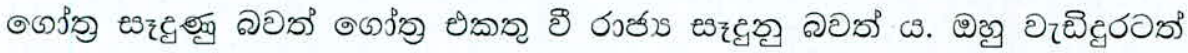

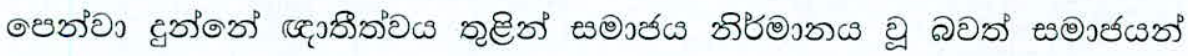

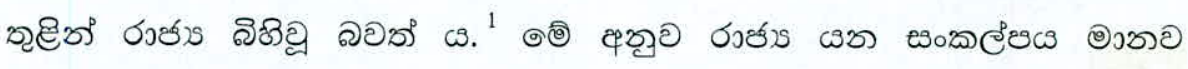

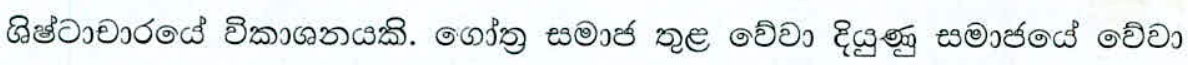

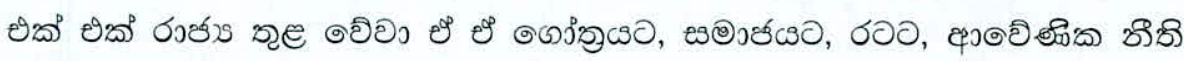

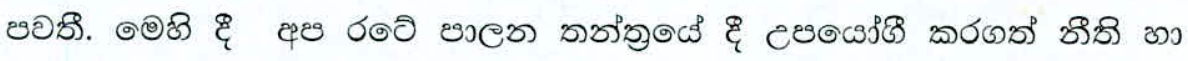

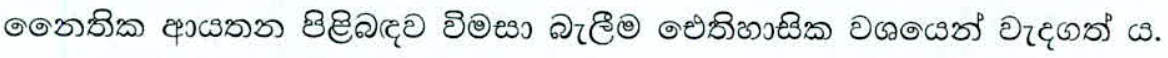

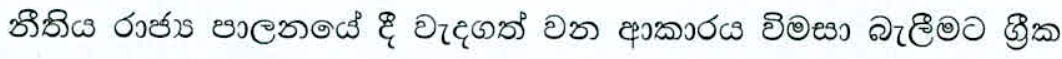

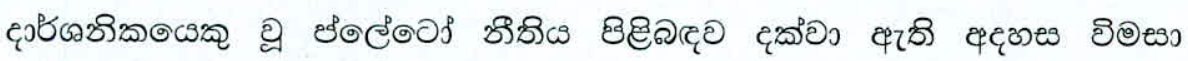

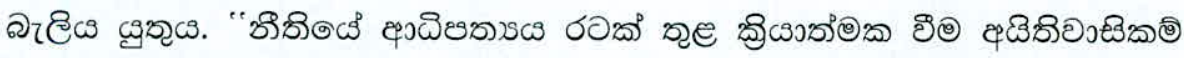

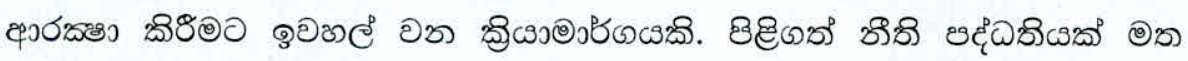

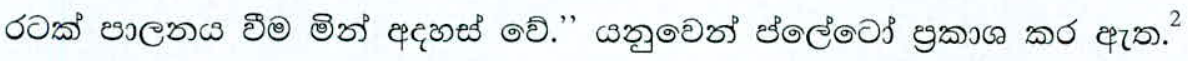

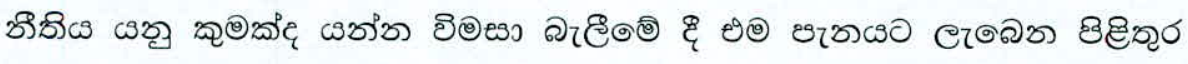

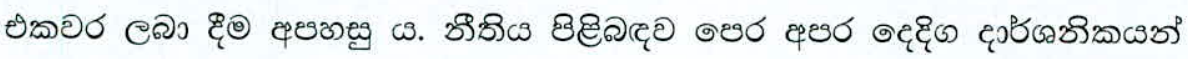

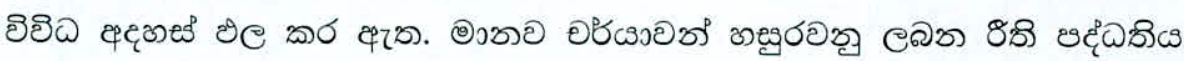

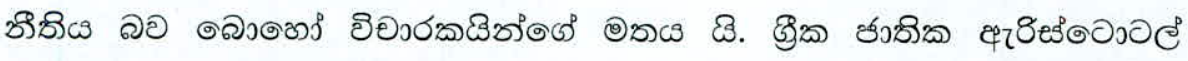

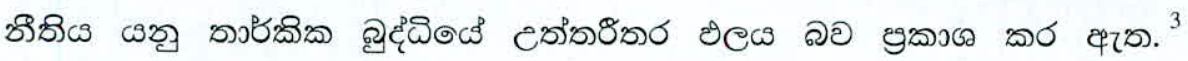

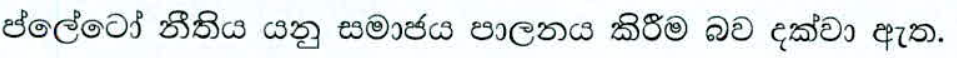

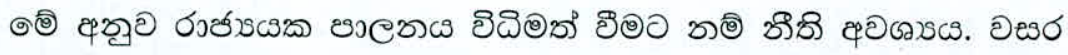

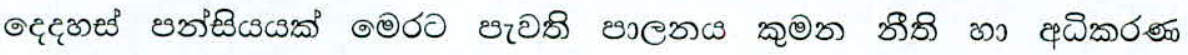

\footnotetext{
${ }^{1}$ Henry main, ancient law it's connections with the early history of society, and it's relations to modern ideas, London, John marry com., 1861, p.63

${ }^{2}$ Allen R.E., Plato : the republic new heaven : Yale University Press, 2006, p.73

${ }^{3}$ Boorker, Sir Earnest, the political thoughts of plato and aristotal, London, p 48
} 


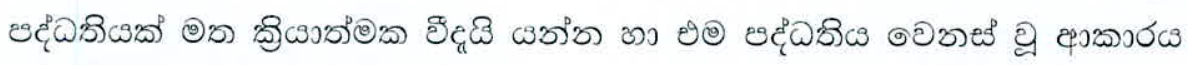

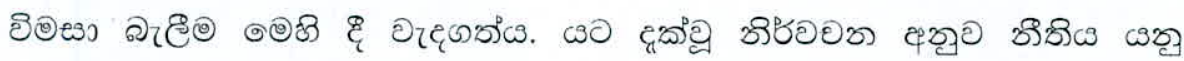

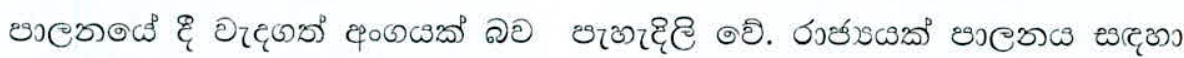

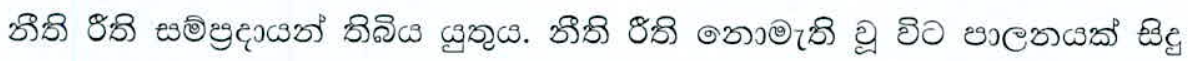

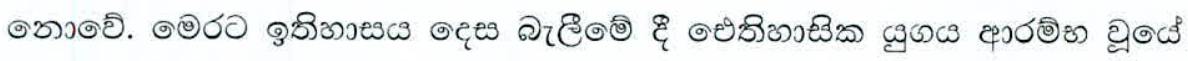

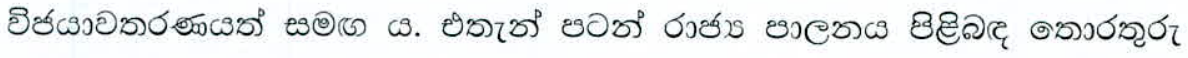

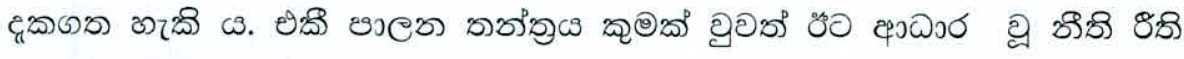

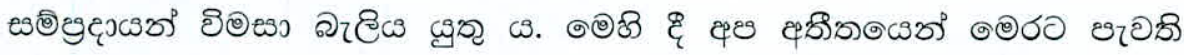

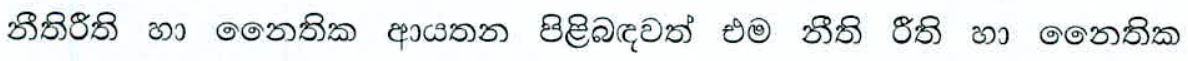

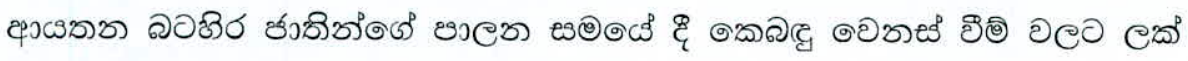

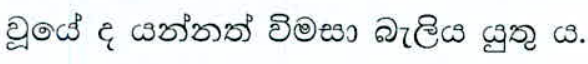

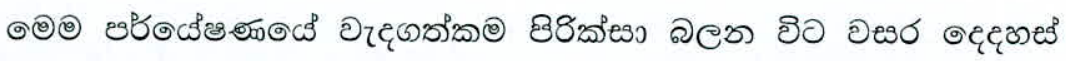

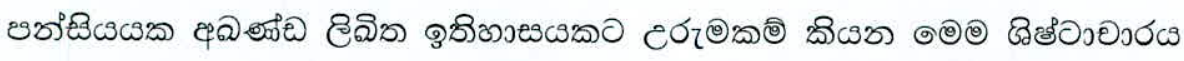

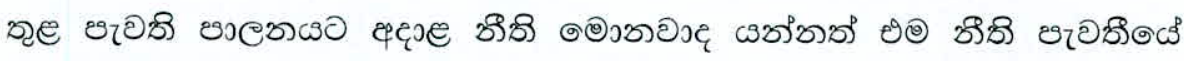

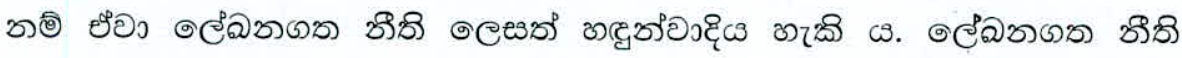

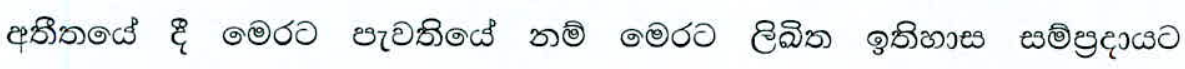

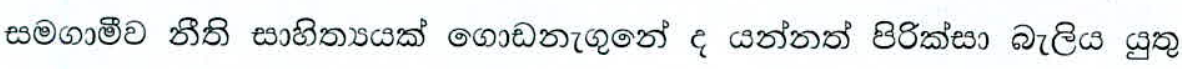
$\omega$.

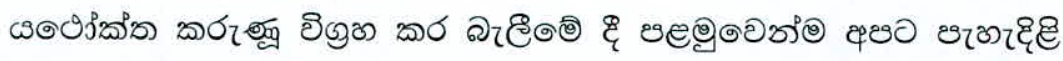

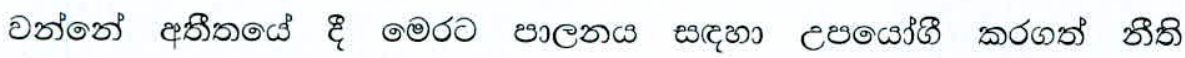

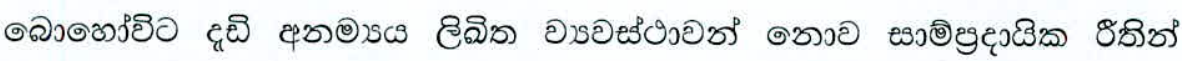

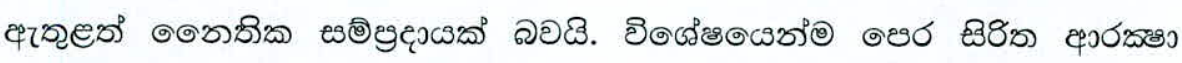

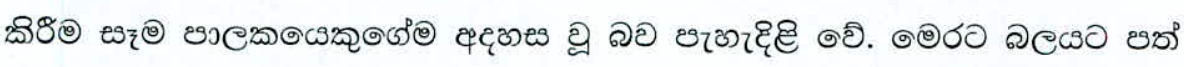

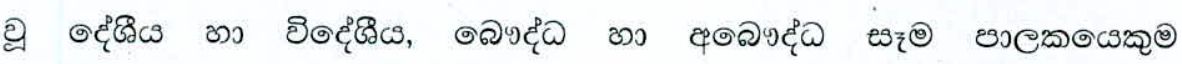

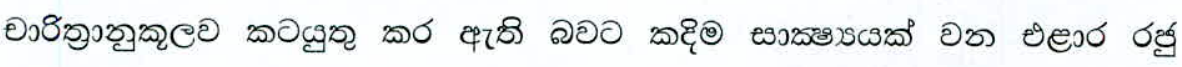

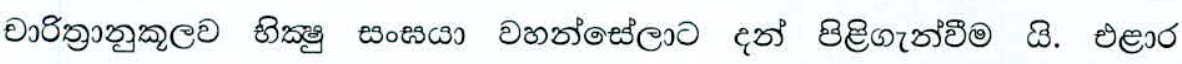

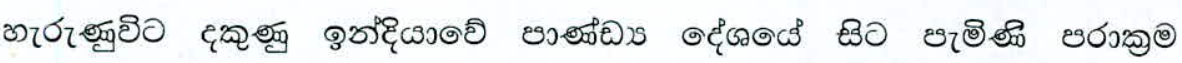

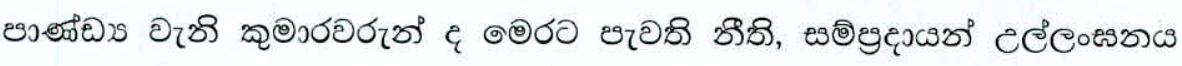

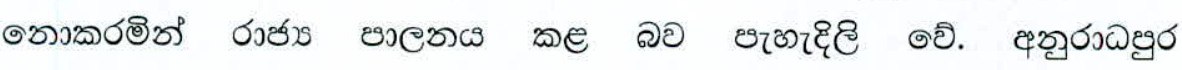

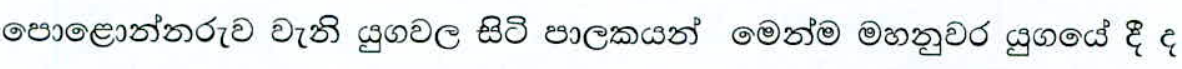

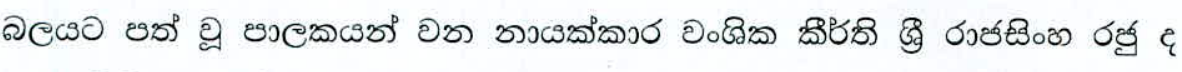

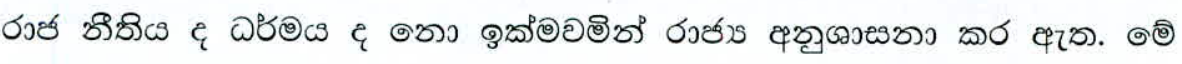




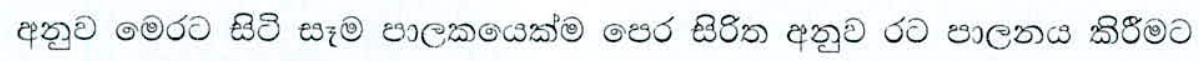

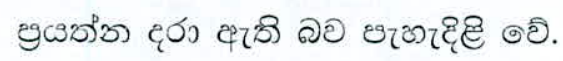

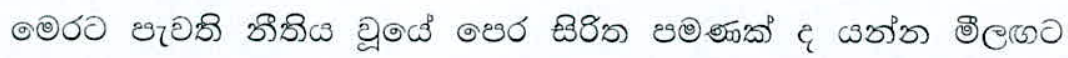

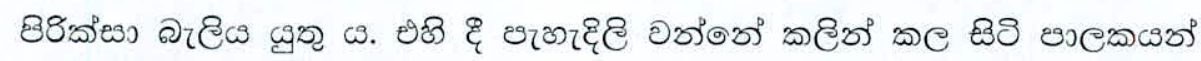

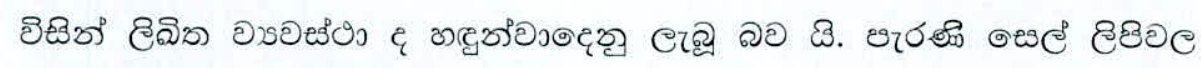

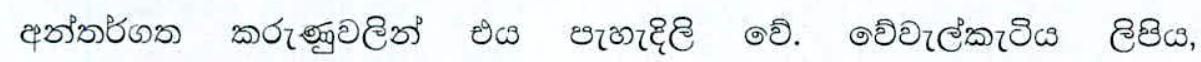

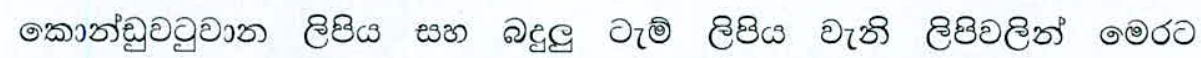

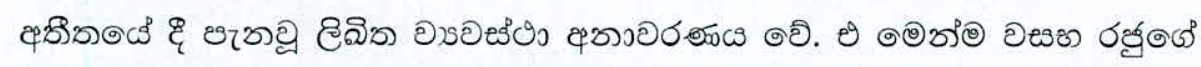

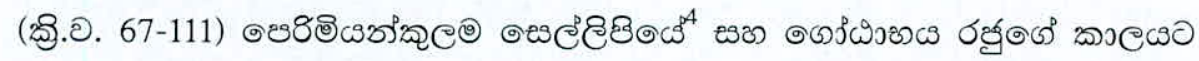

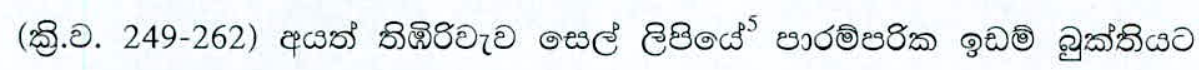

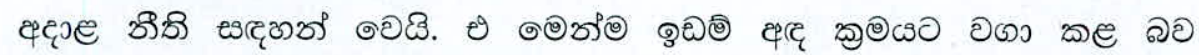

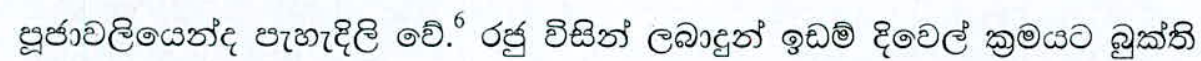

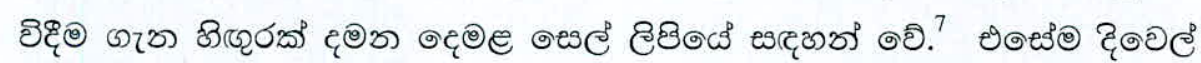

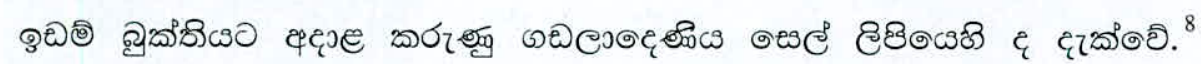

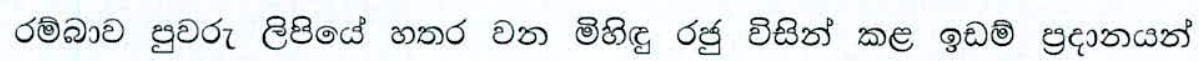

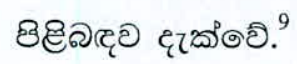

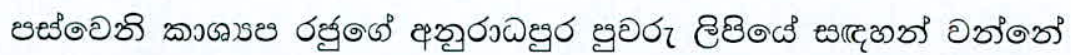

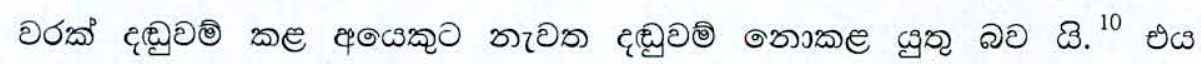

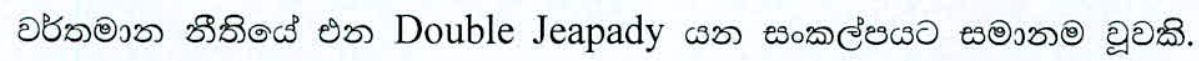

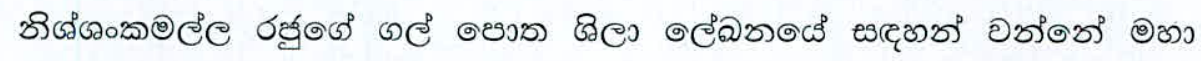

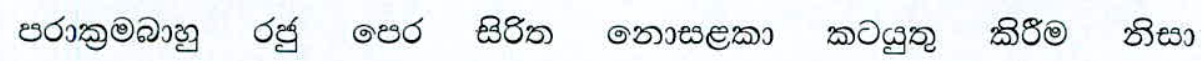

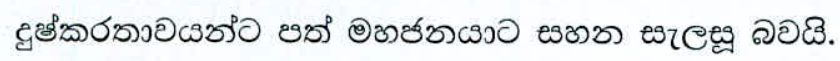

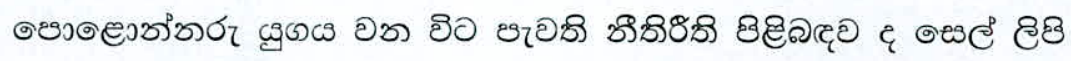

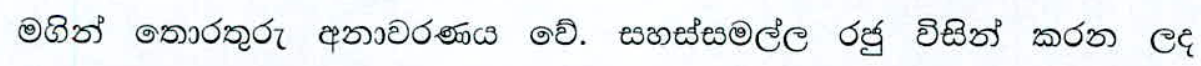

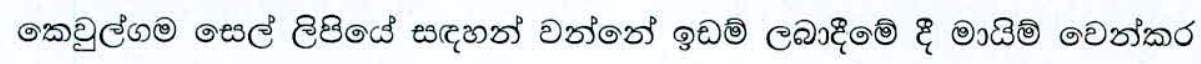

\footnotetext{
${ }^{4}$ EZ Volume 1, No 6 p. 69

${ }^{5}$ EZ Volume 2, No 3 p. 24

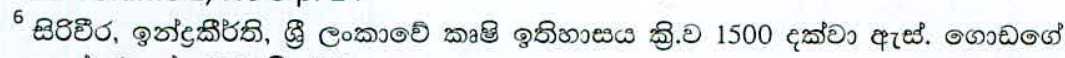

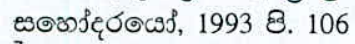

${ }^{7}$ Epigraphia Tamilica K. Indrapala, Volume 1 No, 1 pp. 14-17

${ }^{8}$ EZ Volume 4, No 3 pp. 21-23

${ }^{9}$ EZ Volume 2, No 12 p. 66

${ }^{10}$ EZ Vol. 1, p. 41
} 


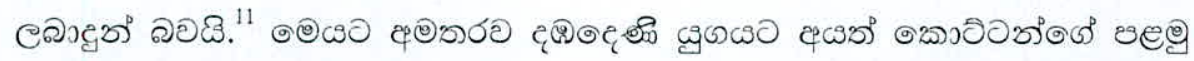

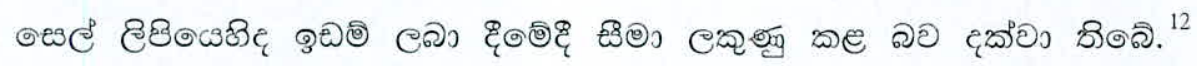

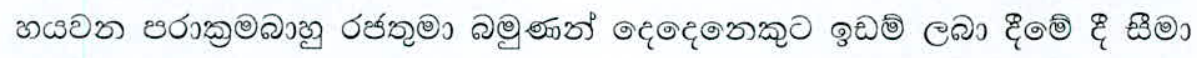

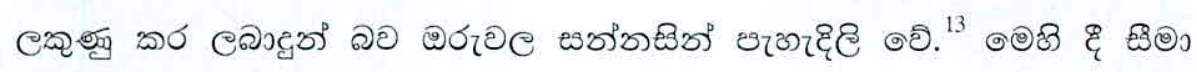

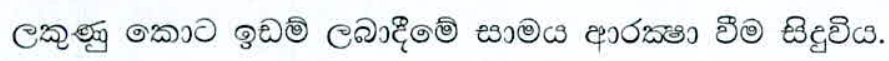

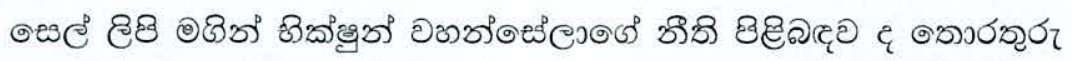

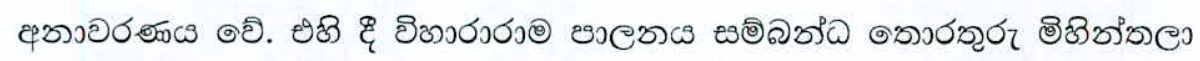

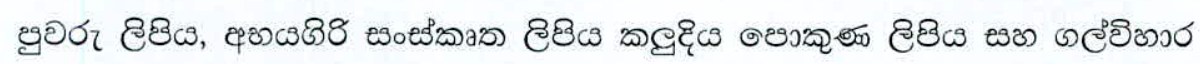

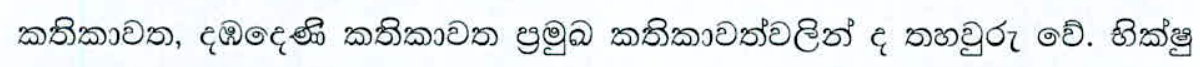

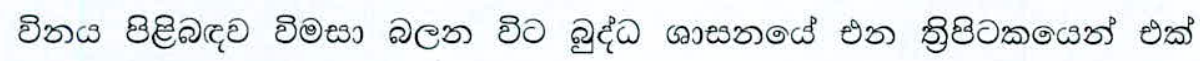

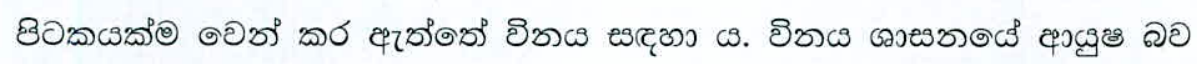

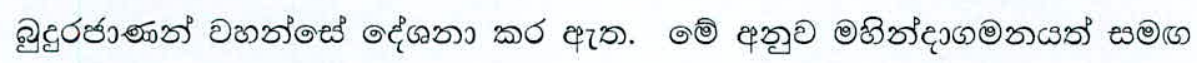

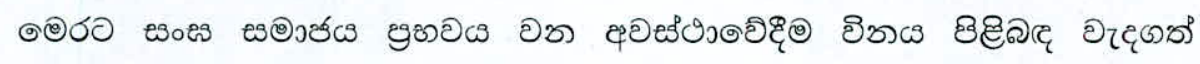

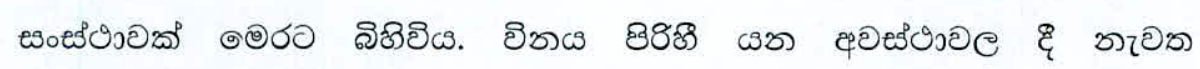

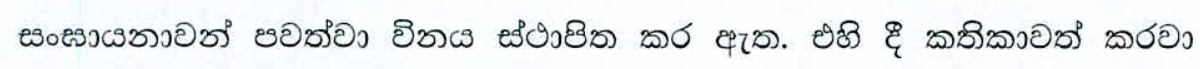

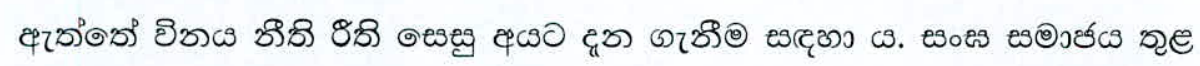

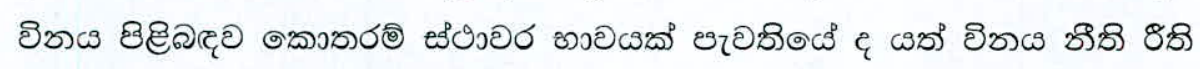

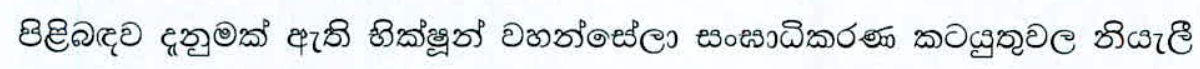

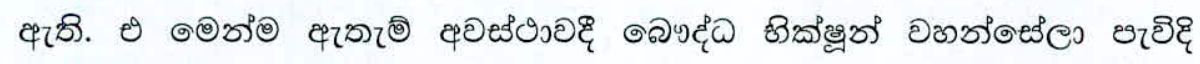

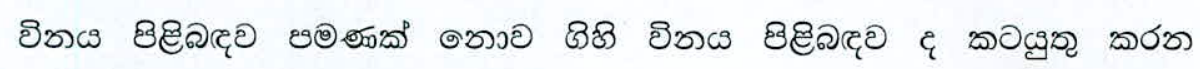

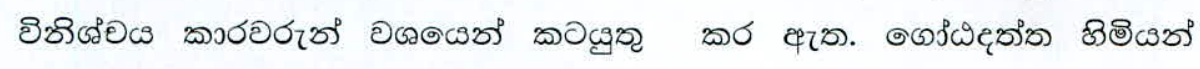

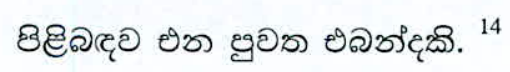

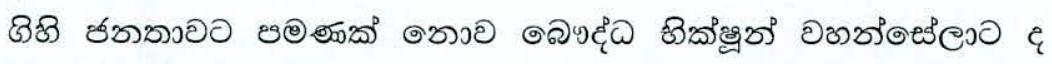

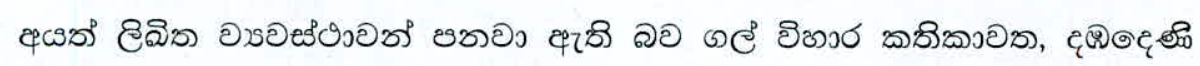

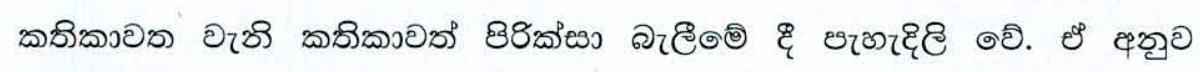

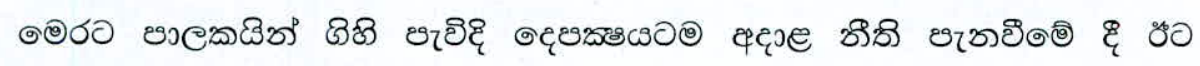

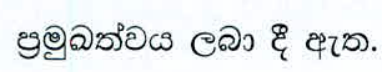

\footnotetext{
${ }^{11}$ EZ Volume 3, No 23 pp. 233-234

${ }^{12}$ EZ Volume 4, No 17 p. 87

${ }^{13}$ EZ Volume 3, No 3 pp. 64-65

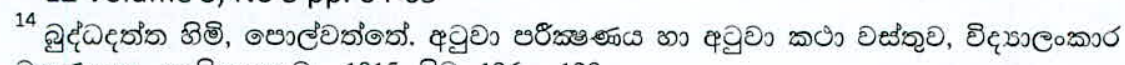

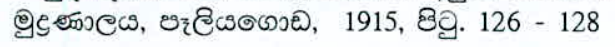




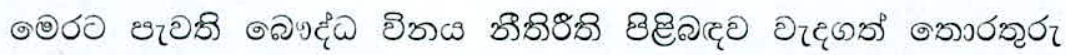

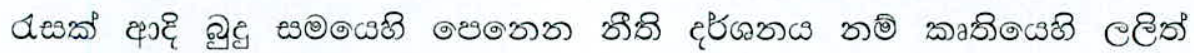

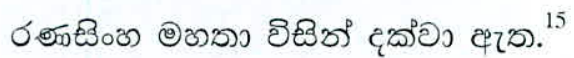

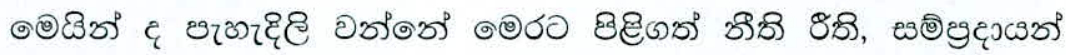
ษอุิ ออ ณ..

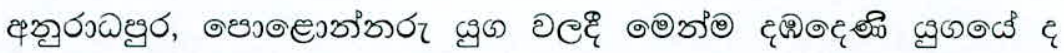

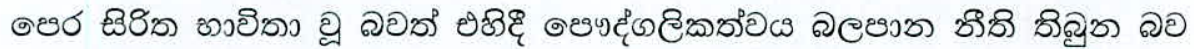

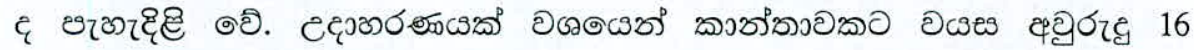

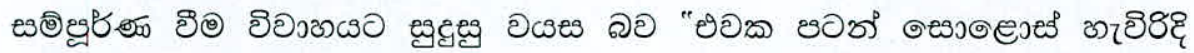

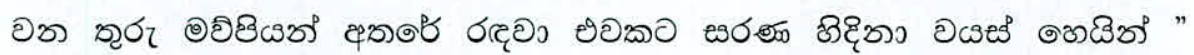

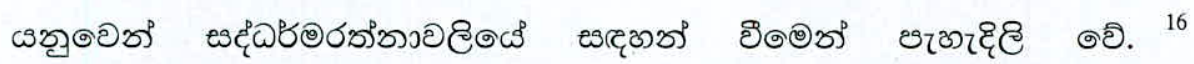

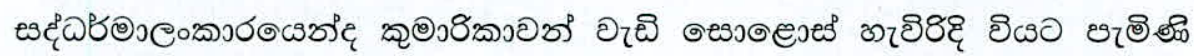

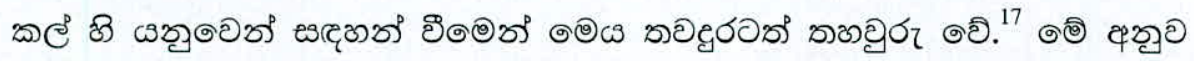

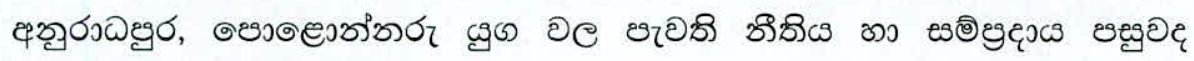

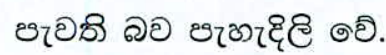

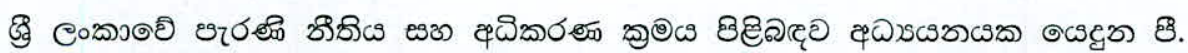

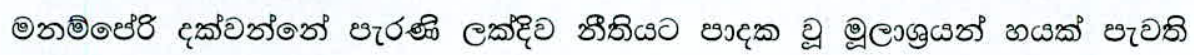
ออณ.. ${ }^{18}$ ย๊อง ๒లి :

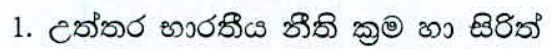

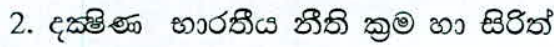

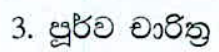

4. ตอ జిరి

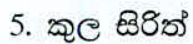

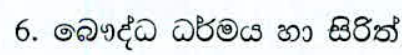

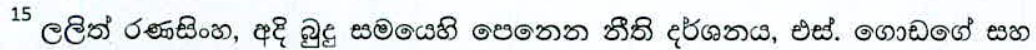

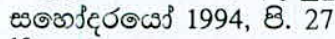

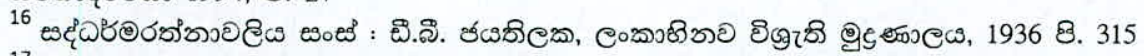

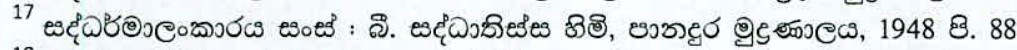

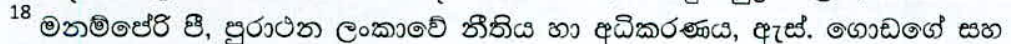

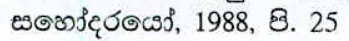




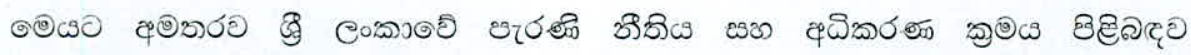

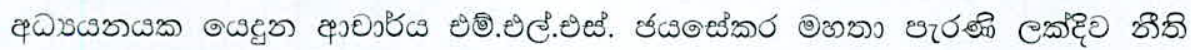

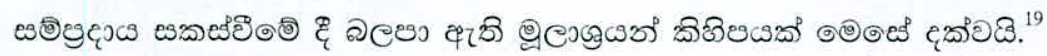

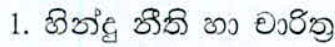

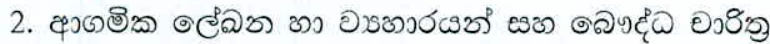

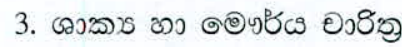

4. ๑๐ర ఱిరకో

5. ฉอ జి8s

6. ตతి జిరికా

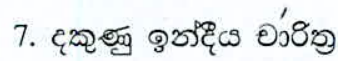

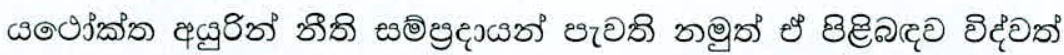

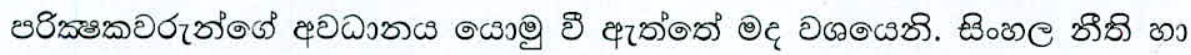

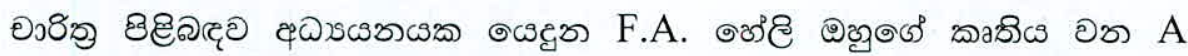

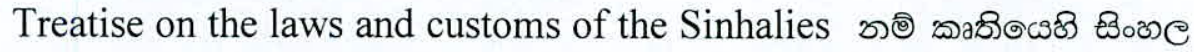

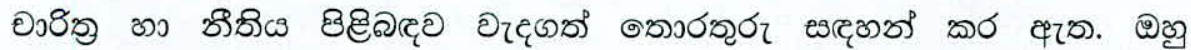

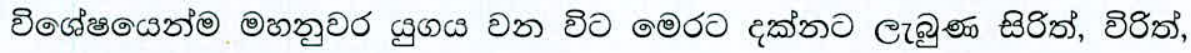

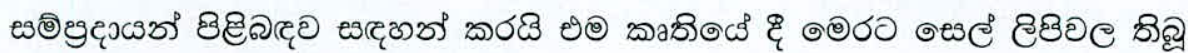

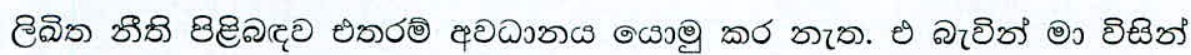

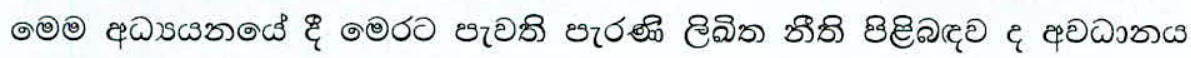

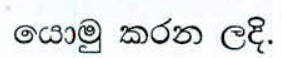

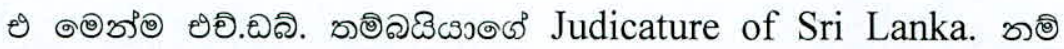

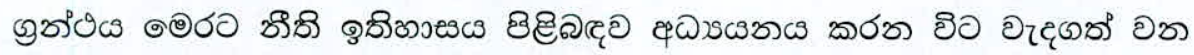

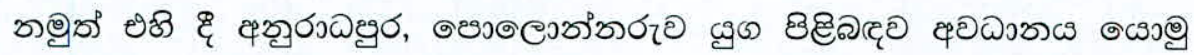

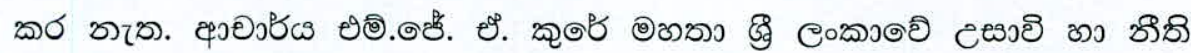

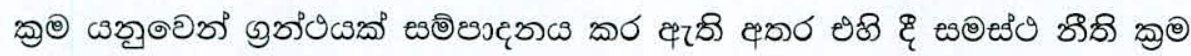

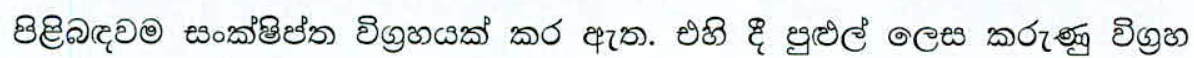

\footnotetext{
${ }^{19}$ Jayasekara M.L.S. The Sources of Sinhalese Customary laws, The journal of Ceylone law, volume 1 No, 1 p. 81
} 